\title{
Teoría y práctica del cuento en Alfonso Reyes
}

\begin{abstract}
$\mathrm{A}$ LFonso Reyes no optó por dedicar su talento a la crcación de obras narrativas. $Y$ no decimos ficticias, ya que Reyes define la literatura como ficción, y su obra es esencialmente literaria. Su genio se manifiesta mejor en la poesía, y cuando escribe prosa, en el ensayo. El ensayo, en verdad, es la modalidad formal a la cual siempre dio preferencia. A ello debido, las narraciones que escribió - con pocas excepciones- más parecen ensayos que cuentos. No vamos aqui a juzgar los relatos de Alfonso Reyes colocándolos en la balanza del género para descubrir si les sobra o les falta peso. Reyes, una y otra vez, manifestó que la crítica no debe de ser preceptiva: Uno de los errores del crítico - que con frecuencia le lleva a conclusiones $y$ apreciaciones erróneas-consiste en querer juzgar de acuerdo con un ideal que se ha formado de antemano de lo que debe de ser éste o aquél género literario. Vamos, más bien, a tratar de encontrar las razones que nos expliquen por qué Reyes dio preferencia a ciertas formas híbridas.

En algunos de sus cuentos, como en esas excelentes fantasias que se llaman "La cena" y. "El fralie converso", Reyes dejó bien demostrado que tenia talento para componer narraciones cortas que se ajustan a los cánones del género y que dejan satisfecho al más exigente de los críticos. Sin embargo, la mayor parte de su producción narrativa no refleja esa tendencia. La razón no se encuentra en la incapacidad del autor para es. cribir verdaderos cuentos, sino en su teoria sobre lo que constituye la buena literatura. Para Reyes, el género literario no es un molde absoluto. Es, más bien, simple tipificación en el tratamiento de los asuntos. " $\mathrm{Y}$ aun. pudiera ser que el autor para adoptar tal o cual asunto - nos dice Reyes-:
\end{abstract}


escape a las costumbres genéricas de su época literaria e introduzca por su cuenta nuevas modalidades, si tiene aptitudes para ello". 1

Aptitudes para introducir nuevas modalidades itterarias Reyes sin duda las tenía. Una de esas nuevas formas de que se vale para dar expre. sión a los asuntos que le atraen es lo que llamaremos el cuento-ensayo, cuyas características nos proponemos deslindar. Mas antes de hacerlo es preciso mencionar otta idea de Reyes en torno a las formas literarias. Para Reyes, la novela es una de las tres funciones formales de la literatura. El término, sin embargo, incluye otras formas narrativas, entre ellas el cuento. "Comprendemos en la Novela - dice Reyes-todos los géneros épicos y narrativos, de todas las épocas, en verso o en prosa, leyendas, cuentos, fábulas o 'ejemplos' didácticos, novelas propiamente tales, antiguas y modernas: el cuento egipcio de los Dos Hermanos; el poema babilónico de Izdubar; el Ramayana de Valmiki..." (Ibid., P, 473). La novela propiamente tal ( $\mathrm{y}$ por lo tanto el cuento), según Reyes, no puede ser objetiva, como querían en el siglo Xrx Flaubert y los realistas, o como lo proponía Henry James o lo deseaba Ortega más tarde. Ya en Igro había Reyes escrito un ensayo, "La cárcel de amor de Diego de San Pedro, novela perfecta", publicado en I9x I en su libro Cuestiones estè. ticas, en el cual reaccionaba contra el realismo objetivo. "Las obras más altas de la humanidad - decía en ese ensayo- son ya, para nesotros, aquellas en que palpita todo un ser, con su personalísimo aliento y su misma vida".2 Los novelistas, continúa Reyes, "se han empeñado en ofrecer también espectáculos impersonales, indiferentes, desinteresados. $E_{n}$ la novela quería Flaubert que el autor, como Dios en el mundo, obrase en todas partes mas no se descubriese precisamente en ninguna especial:

"Mucho he buscado yo el impersonalismo, y en ningtna parte lo he encontrado, y menos en la novela, y menos en las novelas de Flaubert" (Ibid.).

Según Reyes, el novelista no puede, aunque quiera, set impersonal: "Cietto que la teoria del impersonalismo-dice-... puede solamente interpretarse como el contraveneno de la manía declamatoria que consiste en disgustarse con los personajes de la novela o defenderlos en largos discursos; pero esto, al fin, no es personalismo, sino mal gusto; y personalismo es expresar, valientemente, el mundo, como se le mira, sin

1 Alfonso Reyes, "Apuntes para la teoría literaria" en Obras completas de Alfonso Reyes, XV (México: Fondo de Cultura Económica, 1963), p. 467.

2 Alfonso Reyes, "Cuestiones estéticas", en Obras completas de Alfonso Reyes, I (México: Fondo de Cultura Económica, 1955), p. 49. 
preocuparse de que la obra resulte irteal para los muchos, y sin querer que ella responda al criterio de ese hombre abstracto que sería menester concebir, en este argumento, y que sería el semejante del bomo econo. micus de la Economia Politica absoluta" (Ibid., P. 5I). : .

Reyes, en la práctica, sigue su teoria muy de cerca: sus cuentos no son impersonales; el punto de vista no es objetivo. Reyes no cree que el cuentista pueda esconderse tras de su obra; debe, más bien, expresarse en ella. $Y$ eso es precisamente lo que nos of rece Reyes en su cuentoensayo: la expresión personal. El cuento es, por lo tanto, un monólogo no disfrazado. Si Ja novela -se pregunta Reyes-es estéticamente un monólogo, "¿por qué no dejarlo ver, como lo hizo el Bachiller Diego de San Pedro?". (Ibid., p. 58). Y añade: "En cuanto a la novela impersonal ya propuse que es irrealizable, y que aquellas en que el autor está ausente de lo que escribe $y$ aparenta no influir en los personajes tampoco van acordes con la verdad psicológica" (Ibid., p. 59).

El término cuento-ensayo que proponemos no es enteramente arbi. trario. Al deslindar el género novela Reyes afirma: "Hay también géne. ros mezclados que desbordan las previsiones, y que en otro tiempo se llamaron géneros geniales, como lo es la novela-ensayo, que hasta puede. afrontar disquisiciones filosóficas" (XV, 477). Bien que Reyes, no hable de cuento-ensayo, su definición de la novela, como ya hemos visto, incluye el cuento. $Y$ si hay novela-ensayo, ¿por qué no cuento-ensayo? Sin manifestarlo, Reyes ha ensayado uno de esos géneros genitales crean. do el cuento-ensayo, que se caracteriza, en primer lugar, por la introducción, verdadero ensayo en torno al tema que se va a desarrollar en la parte narrativa de la obra; por la presencia del narrador, quien se dirige al lector; por la digresión erudita, que encontramos a cada paso; por el interés en el análisis y la disposición de los materiales, y no en la intriga, y por el estilo personalísimo, cuajado-en el caso de Reyesde imágenes extraidas, más que de la realidad objetiva, del mundo de los libros.

Una de las inovaciones narrativas introducidas por los novelistas y cuentistas del $\mathrm{xxx}$ fue el cambio en el punto de vista del narrador, quien desaparece por completo de su obra. Los modernistas - sobre todo Darío y Nervo- rechazan la objetividad de los realistas y vuelven al punto de vista de los románticos, en donde no se trata de encubrir la presencia del narrador. Lo mismo hace Reyes. Debido a la influencia de Flaubert $y$ James, la tendencia en el cuento y la novela modernos ha sido hacia la objetividad. Un crítico reciente, el venezolano José Fabbiani Ruiz, ha hecho esta observación: "hemos creido siempre que los 
dos géneros narrativos de mayor importancia-la novela, el cuento-, deben conservar siempre una absoluta independencia, no permitir que dentro de la acción se mezcle quien los crea, ya que de suceder esto último el cuento y la novela se convertirían en géneros híbridos". ${ }^{3} \mathrm{Ya}$ hemos visto que Reyes rechaza ambas ideas: el punto de vista objetivo y la rigidez en los géneros. En el caso de Reyes, la presencia del autor no convierte el relato en panfleto político o en diatriba personal; como teme Fabbiani Ruiz. Reyes, artista consciente, nunca abandona la posición puramente estética.

Fácil, y a veces peligroso, es identificar al narrador con el autor. El niño personaje que relata en primera persona en el cuento " $L a$ primera confesión", que principia "Se abría junto a mi casa la puerta menor de un convento de monjas Reparadoras. Desde mi ventana sorprendía yo, a veces, las silenciosas parejas que iban y venian", ${ }^{4}$ no tiene que ser forzosamente Alfonso Reyes. Pero si es extraño que an niño, por perspicaz que sea, se dirija al lector y le diga: "Tú, lector, si llegas a saber - que sí lo sabrás, porque eres muy sabio- dónde está la tumba de Heinrich Bebel, el Bebelius del renacimiento alemán, grítale esta historia por las hendeduras de las losas, ipara que la ponga en metros

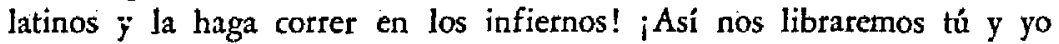
de sus llamas nunca saciadas!" (Ibid., p. 33).

En el cuento "El rey del cocktail" el narrador, Mr. Waldo Higgins y Martínez, nativo de Ottawa, de padre mexicano y madre yanqui, pro. nuncia en Londres un discurso sobre los cocktails. "Su discurso-dice Reyes-no es conocido en español. Lo traduzco a continuación, extractándolo, $y$ lo divido en partes para la comodidad de la lectura".s Aun. que al lector del cuento no le queda ninguna duda de que el narrador, el rey del cocktail, es un gran erudito - cita a Cocteau, Maupassant, Jane Austen, Rabelais, Shaw, Stevenson, Lamb, etc.-y un gran viajero -ha estado en el Estado de Guanajuato, su tierra paterna-, nos ex. traña que al citar a Ruiz de Alarcón lo llame "nuestro ecuánime don Juan Ruiz de Alarcón" (p. 45). En sus obras de crítica, más de una vez Reyes se refiere al autor de $L a$ verdad sospechosa llamándolo "nues. tro Ruiz de Alarcón". 6 El mismo personaje, el rey del cocktail, dice: "Un amigo mío esconde por ahí un cuento inédito, el cuento del que se em. briagaba con sangre de gallo". 7 En su obra "Pasado inmediato", Reyes nos

3 José Fabbiani Ruiz, Cuentos y cuentistas (Caracas, 1951), p. 26.

4 Obras completas, III (México, 1956), p. 31.

5 Quince presencias (México, 1955), pp. 37-38.

6 Ver, por ejemplo, Obras completas, IV (1956), 428, y XIV (1962), 369.

7 Quince presencias, p. 39. 
revela al nombre del anigo que esconde el cuento inédito; trátase de Julio Torri, amigo de Reyes. "El cuento, en manos de Torri-escribe Reyes en "Pasado inmediato" - se hacía crítico y extravagante. (Nunca publicó él sus páginas de entonces: el embustero que privaba de existencia a los que nombraba, el que se embriagaba con sangte de gallo, el descabezado que traía la cabeza pegada y no podía acercarse al fuego para que no se le derritiera el pegamento)". ${ }^{8}$ El propósito de Reyes al no deslindar al narrador del autor es el de dar a su narración un aire personal, el de evitar el vacío de lo impersonal, que Reyes aborrece.

Otro medio de que el autor se vale para hacer constar su presencia es el uso, dentro del relato, de citas, alusiones, referencias y hasta digre'siones eruditas. A veces, la nota erudita tiene función estructural; así ocurre en "El rey del cocktail", en donde el discurso sobre vinos y licores del protagonista es tu derroche de erudición culinaria. En apropiada nota, el autor nos dice: "Confieso haber aprovechado algunos datos de este discurso en mis Memorins de cocina y bodega, posteriormente publicadas, I954" (Ibid., p. 38). Otro ejemplo de este enlaza. miento lo encontramos en el relato "El testimonio de Juan Peña", en el cual hace uso de ciertos recuerdos personales para caracterizar al narrador; en ellos se refiere a "los muchachos de mi generación", aunque sin hacer una referencia concreta. En su ensayo "Pasado inmediato", al hablar de la generación del Centenario, a la cual pertenecía Reyes, nos dice: "Permitidme ahora que cite otro documento de la época, que puede servirnos de sintesis". ${ }^{9} \mathrm{El}$ documento de la época es, por supuesto, parte de "El testimonio de Juan Peña". En "Los dos Augures", arranque de novela, pone Reyes en boca de uno de los personajes una anécdota que, según nos dice en su ensayo "Debate de la cordura y la locura", del libro Los trabajos y los dias (I945), le contó en Madrid don Fernando Pimentel y. Fagoga; así descubrimos quién se encubre bajo el nombre ficticio Juan Antonio Rosales que se le da a Pimentel en el cuento.

Lo interesante en cuanto a la erudición de.Reyes en sus cuentos es que no importa cuál sea el tema $\rightarrow y$ hasta podríamos pensar que el deseo de dar expresión a su basta erudición le hace imaginar el resto del cuento- este aspecto del relato siempre es brillante. Aun cuando el tema sea insignificante, como lo es en el cuento "En las repúblicas del Soconusco", Reyes encuentra medios para lucir su vasta erudición. ¿Quién podría set erudito, como lo es este súbdito alemán que nos cuenta sus aventuras en Soconusco, sobre el insignificante tema del palillo de dien-

8 Pasado inmediato y otros ensayos (México, 1941), p. 46.

9 Arbol de pólvora (México, 1953), pp. 68.69. 
tes? Pues no le faltan a Reyes citas en torno a este desdeñable objeto, sacadas de La verdad sospechosa ("que han de ser oro las pajas/cuando los dientes son perlas"), del Panchatantra, de Polidoro Virgilio," de Diego de Urrea. Por supuesto que aquí la intención de Reyes es burlarse de la erudición alemana. El protagonista de su cuento llega hasta "a escribir toda una disertación metafísica sobre el limpiadientes: Der Zabn. stocber als Wille and Vorstellung. Don Jacintito [el otro personaje] llegó a creer-dice el súbdito alemán-que mis indigestiones eruditas eran una forma del genio mercantil" (O.C., III, 47-48).

Otro método utilizado por Reyes para evatir lo impersonal es el que consiste en hacer uso de personajes sacados de las lecturas, en torno a los cuales imagina, o prolonga, escenas que reflejan su propia reacción hacia la obra ajena. Excelente ejemplo de esta técnica es el cuento "El fraile converso (Diálogo mudo)", en donde Reyes conjetura la suerte de dos personajes de una comedia de Shakespeare.

Acaba de caer el telón sobre un mundo maravilloso. El público discute a Shakespeare, a la luz de las unidades dramáticas. Claudio está dispuesto a reparar el honor de la que había ultrajado. Mariana se apresta a ser feliz. Angelo, a amarla, arrepentido. Escalo espera que el Duque sepa recompensar sus servicios. El Preboste confía en que se le dé un puesto más digno de su discreción. Isabel y el Duque se enamoran, pasados ya los sobresaltos de aquélla, y hecha ya por éste la famosa justicia. Lucio pasa por casarse, a condición de no ser ahorcado. El verdugo, verdugo queda; el bufón necio; y la señora Overdone, casamentera.

Fray Pedro tira penosamente del borracho Bernardino, que no se decide a seguirlo...

El Duque ha dicho a fray Pedro:

-Religioso, lo dejo en vuestras manos; aconsejadlo.

$$
\text { (O.C., III, 55) }
$$

De aquí en adelante, Reyes echa a volar la imaginación. El fraile se lleva al borracho, pero no sabe qué hacer con él. El personaje, Fray Pedro, maldice al dramaturgo por haber dejado su drama a medio ha. cer; "reniega de los puntos suspensivos; abomina de la lentitud o negligencia del comediógrafo que llega a un quinto acto dejándole al pobre fraile aquella prenda en las manos; piensa que el libre albedrio es 10 peor, y que menos mal mientras el autor se encarga de moverlos con invisibles hilos sobre el escenario del teatro. Pero ahora, abandonados 
a sí mismos, ¿qué hacer, qué hacer por esas calles de Dios?" (lbid., PP. $\therefore 55-56)$.

Fácil es determinar que se trata de la comedia Measure for Measure, aunque Reyes no la mencione. En este cuento, que lleva la fecha I9r3, Reyes se adelanta a la técnica de Pirandello en cuanto al intercambio entre el perșonaje y el autor. Fray Pedro se desespera con Shakespeare porque éste dejó sin decidir la suerte del borracho. Impacientemente, Fray Pedro termina lo que Shakespeare dejó incompleto: mata al borracho. "Y el fraile se sienta en el suelo sin saber qué hacer de su albedrío, dándose cuenta de que es el borracho asesino el que ha hecho de él su catecúmeno y su converso" (p. 57).

Pero todavía hay más. Reyes hace aparecer a Shakespeare: "Caído casi de la luna, Shakespeare, a gatas, baja, por un tejado en declive; contempla la escena: saca un compás, una brújula, una plomada, un astrolabio... Hace cálculos sobre la pizarra del techo, y concluye que aquélla es la prolongación única de las líneas que él dejó trazadas en la última escena de su comedia" (p. 57).

Como es evidente en este cuento, Reyes no rehuye la nota fantástica, aunque sí evita a toda costa la nota costumbrista. Su relato "Pittiflauts", de la colección Arbol de pólvora (1953), termina de esta manera sarcástica: "Y. así podemos seguir indefinidamente, desarrollando las posibilidades del fantasma contenidas en su misma definición: De cómo Pittiflauts de Oklahoma fabricó, él solo, un automóvil; de por qué Mr. Pittiflauts se hurgaba a dedo las narices; y cuáles, según Mr. Pitti. flauts, sean los mejores modos de cortar las verrugas. Pero ¿para qué, lector, para qué? El costumbrismo tiene sus límites y es poesia de corto alcance" (p. 88). En cambio, la nota fantástica reaparece con frecuencia en los relatos del regiomontano. Ya su primer cuento, "Ia cena", es el resultado de una experiencia onírica, como el autor mismo confesó. La linea entre lo real y lo irreal, para Reyes, fue siempre tenue: "Porque basta-nos dice en su ensayo "Cuenta mal y acertarás"- un ligero esfuerzo o un leve descuido para salirse definitivamente de aqui (para escapar de esto donde el objeto abandonado a sí mismo cae por tierra) y echarse a volar sin darse cuenta. Porque basta un instante de reflexión para comprender que lo divino comienza donde ya dos y dos no cuadran, sino triangulan, exagonan, exageran o qué se yo".

Otro ejemplo de lo fantástico en Reyes lo encontramos en "La Retro", esbozo de un personaje, en donde se anticipa a Carpentier y su "Viaje a la semilla". La Retro, debido a un accidente automovilistico, queda afectada de un raro mal: todo lo hace hacia atrás: comenzó por 
andar hacia atrás; "a poco dio en pedir la cena por la mañana y el desayuno por la noche... también contaba los números al revés y relataba los sucesos en sentido inverso, reculando por la ley de causalidad... creció para abajo, y al fin entró en la muerte como un zambullidor en la alberca" (Ibid., pp. 90-91).

Los de Reyes no serán - con pocas excepciones- cuentos herméticos, objetivos; pero tampoco lo son fríos, impersonales, indiferentes, desinteresados. No hay duda de que en ellos palpita todo su ser, con su personalísimo aliento y su misma vida. En este sentido, Reyes se ade. lanta a su tiempo. Parece que el cuento y la novela, en sus últimas manifestaciones, abandonan ese interés en la técnica objetiva para volver a dar importancia al fondo anímico del autor. Los cuentos-ensayos de Reyes han marcado una pauta, ya discernible en Borges y sus contemporáneos, manifiesta en los jóvenes cuentistas hispanoamericanos que hoy cultivan el género.

University of Illinois

LuIS L.EAL 